\title{
Balloon-Assisted Coiling
} of the Cavernous Sinus to Treat Direct Carotid Cavernous Fistula

\section{A Single Center Experience of 13 Consecutive Patients}

\author{
ALIOSCIA DE RENZIS ${ }^{1}$, SERGIO NAPPINI ${ }^{2}$, ARTURO CONSOLI ${ }^{2}$, \\ LEONARDO RENIERI ${ }^{2}$, NICOLA LIMBUCCI ${ }^{2}$, ANDREA ROSI ${ }^{1}$, CHIARA VIGNOLI ${ }^{1}$, \\ GIANNANTONIO PELLICANOे ${ }^{3}$, SALVATORE MANGIAFICO ${ }^{2}$ \\ ${ }^{1}$ Department of Radiology, ${ }^{2}$ Interventional Neuroradiology Unit, ${ }^{3}$ Department of Neuroradiology, Careggi University \\ Hospital; Florence, Italy
}

Key words: carotid cavernous fistula, coiling, endovascular treatment

\section{Summary}

This study evaluated clinical and neuroradiological results in 13 consecutive patients with spontaneous and traumatic direct carotid cavernous fistulas treated at our center between January 2006 and September 2012.

All patients were treated by coiling of the cavernous sinus. Coiling was always performed while a semi-compliant non-detachable balloon was temporarily inflated in the internal carotid artery. This technique (balloon-assisted coiling) permitted a clear visualization of the fistula, facilitated coil positioning and protected the patency of the artery. All patients' clinical data and radiological examinations were reviewed; nine patients underwent radiological and clinical follow-up, with a mean duration of 3.8 years (range: six months-six years). Overall results at discharge showed a complete occlusion of the fistula in seven patients $(7 / 13,54 \%)$ and a resolution of symptoms in eight patients $(8 / 12,67 \%)$. Radiological follow-up showed complete occlusion of the fistula in all patients $(9 / 9,100 \%)$ and clinical follow-up showed a resolution of symptoms in eight patients $(8 / 9,89 \%)$ and persistent symptoms in one $(1 / 9,11 \%)$. No procedure-related complications occurred.

Balloon-assisted coiling of the cavernous sinus for the treatment of direct carotid cavernous fistulas proved an effective and safe technique, both in angiographic and clinical terms, and may be considered a technical improvement.

\section{Introduction}

Direct carotid-cavernous fistulas (DCCFs) are abnormal arteriovenous shunts between the internal carotid artery (ICA) and the cavernous sinus. They can be classified as spontaneous or traumatic; spontaneous DCCFs usually derive from rupture of intracavernous aneurysms, while traumatic shunts are secondary to head trauma or penetrating injuries. DCCFs can also be classified according to the flow rate into high, intermediate, or low flow. In highflow CCFs, the inflow from the ICA is completely directed through the fistula without filling of the intracranial vessels. In intermediateflow CCFs, both the fistula and intracranial vessels receive blood from the ICA, while in low-flow CCFs only slow and sluggish filling of the cavernous sinus is present ${ }^{1}$. In most of the cases clinical presentation includes proptosis, chemosis, orbital bruits, and headache. Additionally, the majority of patients may suffer from visual disturbances, including diplopia, ophthalmoplegia and orbital pain due to cavernous sinus hypertension and eye muscle edema caused by venous congestion. Venous hypertension on cortical veins can lead to subarachnoid hemorrhage; this event occurs in 5\% of patients 2,3 .

Rapid endovascular technical development has provided safe and effective treatment strategies for DCCFs with detachable balloons ${ }^{2-6}$, detachable coils ${ }^{7-10}$ or covered stents ${ }^{11,12}$, al- 


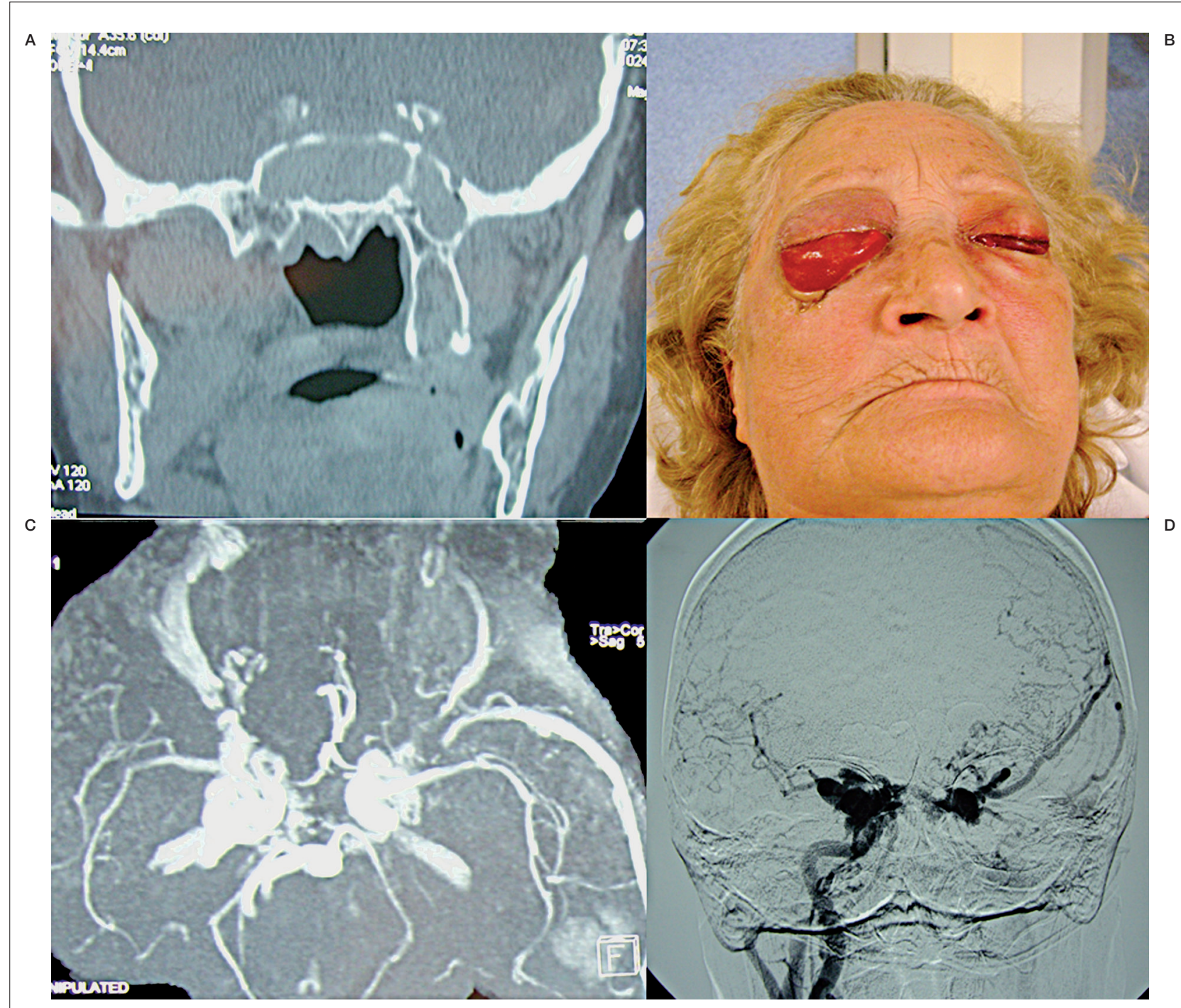

Figure 1 A) Computed tomography showing fracture of the basicranium. B) Patient $\mathrm{n}^{\circ} 8$ before treatment; bilateral proptosis, chemosis and ptosis, more prominent on the right side. C) Pre-treatment magnetic resonance angiography showing early visualization of the right and left cavernous sinuses, both enlarged, and early visualization of the right and left superior ophthalmic veins. D) Digital subtraction angiography showing the right direct carotid-cavernous fistula.

though all devices have shown some disadvantages. The purpose of this study was to evaluate the clinical and neuroradiological results in 13 consecutive patients with a DCCF treated at our center by balloon-assisted coiling of the cavernous sinus between January 2006 and September 2012.

\section{Materials and Methods}

\section{Patients}

Thirteen consecutive patients (seven females and six males, mean age: 53.7 years) with a di- agnosis of DCCF were treated at our center between January 2006 and September 2012. Seven out of 13 (54\%) fistulas were spontaneous and six out of 13 (46\%) were traumatic; fistulas were right-sided in seven patients $(54 \%)$, left-sided in five (38\%) and bilateral in the other case $(8 \%)$.

The most frequent symptoms included proptosis in ten patients $(77 \%)$, chemosis in nine patients $(69 \%)$, diplopia in seven patients $(54 \%)$ and transcranial bruit in four patients $(31 \%)$. Other symptoms observed were tinnitus, headache, ptosis, loss of visus, anisocoria and hypoesthesia in the territory of the ophthalmic nerve. 


\section{Diagnosis}

Ten patients underwent magnetic resonance (MR) and MR angiography (MRA). The diagnosis was made based on the visualization of the venous system during the arterial phases showing ectasia of the cavernous sinus and of the ipsilateral superior ophthalmic vein. MR and MRA established a definite diagnosis in four of these patients, showing symptoms strongly correlating with a DCCF. In the other six patients the diagnosis was achieved by subsequent digital subtraction angiography (DSA). In two patients a CT scan suggested the hypothesis of a DCCF and the definitive diagnosis was established with a subsequent DSA. One patient directly underwent DSA because of massive epistaxis after head trauma.

\section{Treatment}

Informed consent was obtained from all the patients. Treatment was performed under general anesthesia and systemic heparinization (except for patient $\mathrm{n}^{\circ} 5$ who had no systemic heparinization because of polytrauma and SAH), with monitoring of the ACT levels. A balloon occlusion test (BOT) was performed before every procedure. Coiling of the cavernous sinus was always performed while a semicompliant balloon (Hyperglide $4 \times 15 \mathrm{~mm}$, Ev3Covidien, Irvine, CA, USA) was positioned in the ICA, near the laceration of the wall. Balloons were inflated in case of protrusion of a coil into the ICA, for a time no longer than 60 seconds. This facilitated the intracavernous positioning of the coils and prevented their carotid migration. The inflation of the balloon also permitted a clear localization of the point of fistula. A controlateral injection, while the ipsilateral ICA was being manually compressed was in some cases performed to permit a better visualization of the point of rupture. The patency of the ICA was preserved in 12 patients $(92 \%)$ whereas in 1 patient ( $8 \%$ ) sacrifice of the ICA was necessary. Coiling of the cavernous sinus was achieved in ten patients using an arterial approach (a microcatheter and a non-detachable balloon both positioned in the ICA); eight patients underwent one procedure (including the patient in which ICA trapping was performed) and two patients underwent two procedures. A bilateral femoral artery access was performed in 11 procedures and a monolateral one in one procedure. In three patients coiling of the cavernous sinus was performed through a transvenous approach (a microcatheter positioned in the inferior petrosal sinus and balloon in the ICA); all these patients underwent only one procedure. The cavernous sinus was achieved through the ipsilateral inferior petrosal sinus (IPS) in two procedures and through the controlateral IPS in one procedure (due to ipsilateral IPS hypoplasia). In all these cases a double access (femoral artery and femoral vein) was needed. In all cases shunt occlusion was achieved with detachable coils. In one case (patient $n^{\circ} 7$ ) a self-expandable stent (Neuroform, Boston Scientific, Freemont, Canada) was released in the intra-cavernous ICA. In another patient $\left(n^{\circ} 4\right)$ trapping of the ICA was needed and was performed and onyx 18 (ev3 Neurovascular, Irvine, CA, USA). No detachable balloons or fibered coils were used in this series.

\section{Peri-procedural evaluation}

The clinical documentation and radiological examinations of all the patients were retrospectively collected and reviewed.

Pre- and post-treatment clinical picture and radiological findings were compared. The postprocedural clinical data of one patient $\left(\mathrm{n}^{\circ} 12\right)$ were lost.

\section{Follow-up}

Nine patients had a clinical follow-up between six months and six years (mean 3.8 years); clinical follow-up was performed by telephone interviews (nine patients) and neurological examination (five patients). Nine patients had radiological follow-up between six months and six years (mean 3.8 years); radiological follow-up was performed by DSA, MR and MRA.

Clinical follow-up was not performed in four patients and radiological follow-up was not done in four patients (Table 1).

\section{Results}

\section{Radiological and clinical results}

Results are summarized in Tables 2 and 3. At discharge $50 \%$ of patients treated through an arterial approach showed complete occlusion of the fistula (5/10) and 78\% had a resolution of symptoms (7/9). The post-procedural clinical data of patient $n^{\circ} 12$ were lost. In these patients the clinical-radiological follow-up showed a 


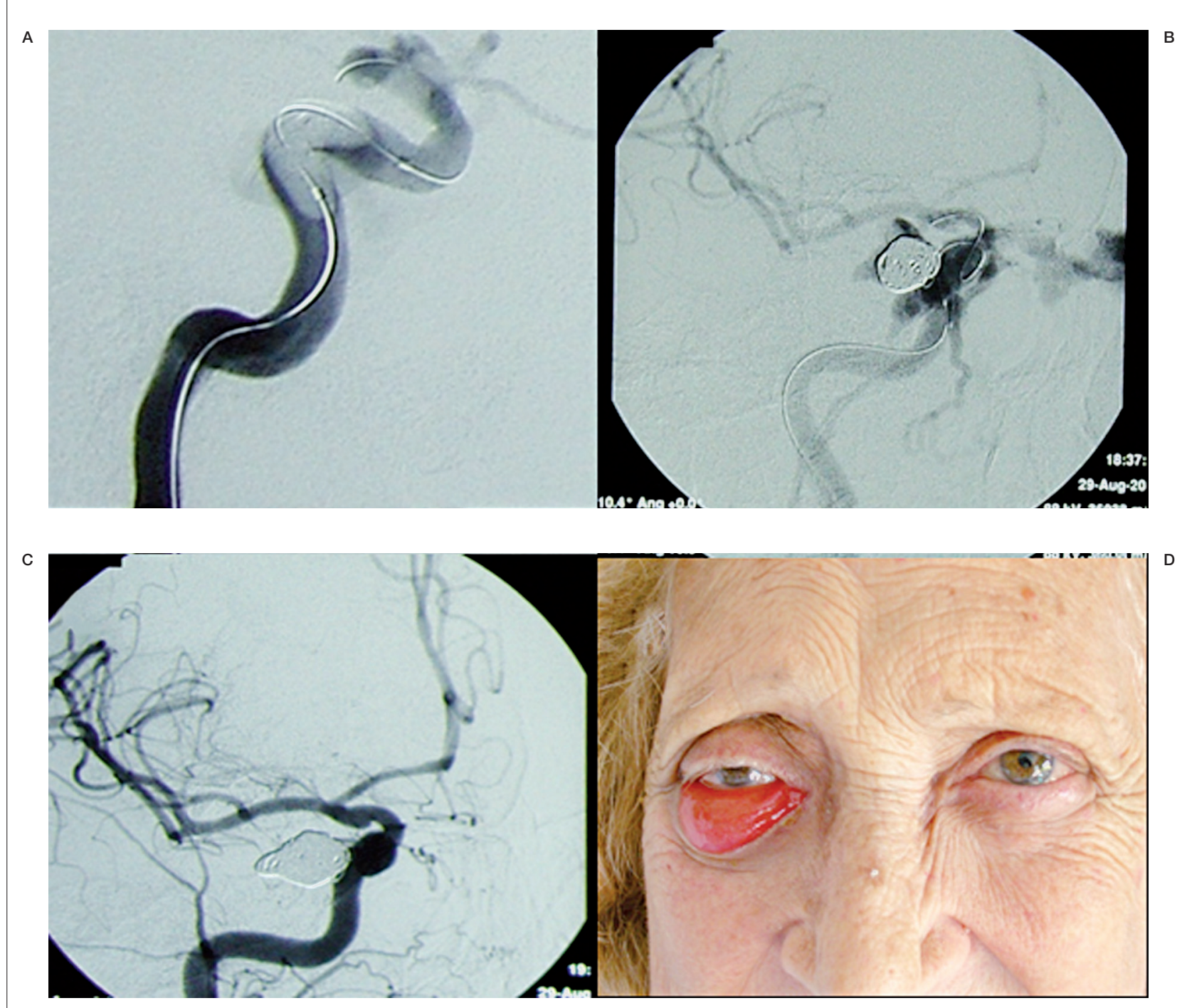

Figure 2 A) Endovascular treatment; balloon inflated in the right internal carotid artery. B) Endovascular treatment; microcatheter in the right inferior petrosal sinus and balloon in the right internal carotid artery. C) Final angiogram showing complete exclusion of the shunt. D) Patient at discharge.

complete occlusion of the fistula in six patients $(6 / 6,100 \%)$ and a resolution of symptoms in six patients $(6 / 6,100 \%)$. Radiological follow-up was not performed in four patients and clinical follow-up was not done in four patients. In patients coiled with a venous approach a complete occlusion of the fistula was observed in two patients $(2 / 3,67 \%)$ and symptoms resolved in one $(1 / 3,33 \%)$. Follow-up showed a complete occlusion of the fistula in all these three patients $(100 \%)$ and symptoms resolved in two cases $(2 / 3,67 \%)$. Persistent symptoms (patient $n^{\circ} 8$ ) were related to partial III cranial nerve palsy (bilateral pupillary light reflex loss and moder- ate ophthalmoplegia); these symptoms were reduced compared with pre-treatment symptomatology. Overall results at the discharge showed a complete occlusion of the fistula in seven patients $(7 / 13,54 \%)$ and a resolution of symptoms in eight cases $(8 / 12,67 \%)$. Radiological followup was possible in $9 / 13$ patients between six months and six years (mean 3.8 years) and showed a complete occlusion of the fistula in all cases $(9 / 9,100 \%)$. Clinical follow up was possible in nine patients between six months and six years (mean 3.8 years) and showed a resolution of symptoms in eight cases $(8 / 9,89 \%)$ and persistent symptoms in one patient $(1 / 9,11 \%)$. 
Table 1 Patients with no clinical and or radiological follow-up.

\begin{tabular}{|cccc|}
\hline Patient & Clinical Follow-up & Radiological Follow-up & Reason \\
\hline 5 & NO & NO & Death \\
7 & YES & NO & Refused \\
9 & NO & NO & Vegetative state \\
11 & NO & NO & Vegetative state \\
12 & NO & YES & Patient lost to Follow-up \\
\hline
\end{tabular}

Table 2 Clinical and radiological results.

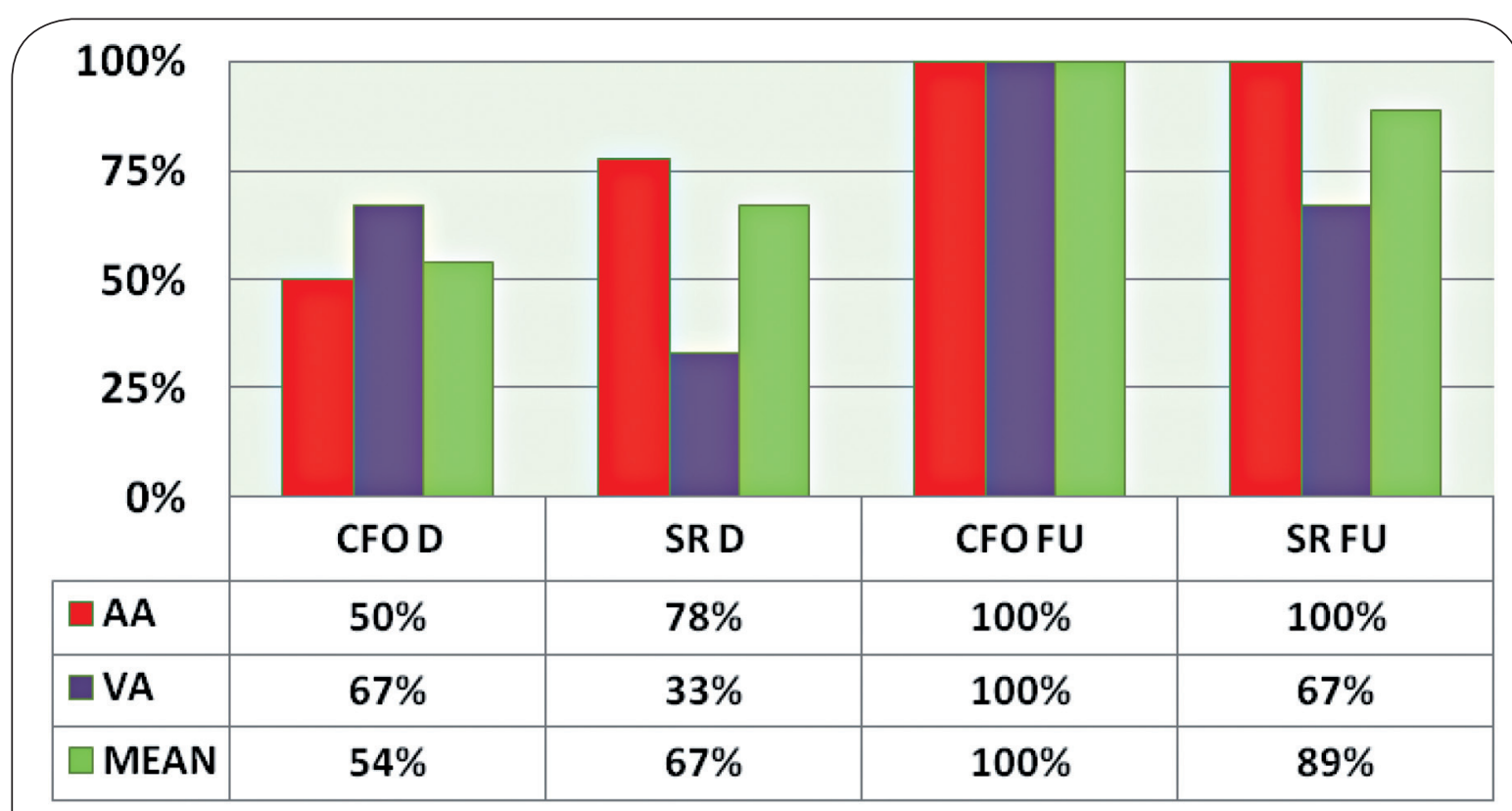

$\mathrm{CFO}=$ Complete Fistula Occlusion; $\mathrm{SR}=$ Symptoms Resolved $; \mathrm{D}=$ at Discharge $; \mathrm{FU}=$ Follow-up; $\mathrm{AA}=$ Arterial Approach $; \mathrm{VA}=$ Venous Approach

\section{Complications}

No intra-procedural or post-procedural complications were observed. The only adverse event was the development of intracavernous pseudoaneurysms. This event occurred in two patients ( $\mathrm{n}^{\circ} 1$ and $2,13 \%$ of the procedures); both patients were treated by coiling using an arterial approach and the pseudoaneurysm had no clinical consequence during follow-up. In patient $\mathrm{n}^{\circ} 1$ the pseudoaneurysm was identified at the three month DSA and the patient refused further controls. Patient $\mathrm{n}^{\circ} 2$ underwent a control DSA control three days after the procedure as the fistula was not completely occluded at the end of the embolization. The angiographic evaluation showed incomplete occlusion of the fistula and the presence of a pseudoaneurysm. Another control DSA after one year showed complete occlusion of the fis- tula and the diameter of the pseudoaneurysm had decreased.

\section{Illustrative case: patient $n^{\circ} 8$}

A 78-year-old woman was hospitalized after a head trauma. CT scan disclosed a fracture of the basicranium (Figure 1A). In the immediately following days the patient developed progressive and bilateral proptosis, chemosis and ptosis, more prominent on the right side, associated with right ophthalmoplegia and bilateral loss of direct and consensual pupillary light reflex (Figure 1B). MR and MRA (Figure 1C) showed early visualization of the right and left cavernous sinuses, both enlarged, and early visualization of the right and left superior ophthalmic veins. The examination also confirmed proptosis. A DCCF was hence suspected and the subsequent DSA confirmed the diagnosis (Figure 1D). The patient underwent endovascular treat- 

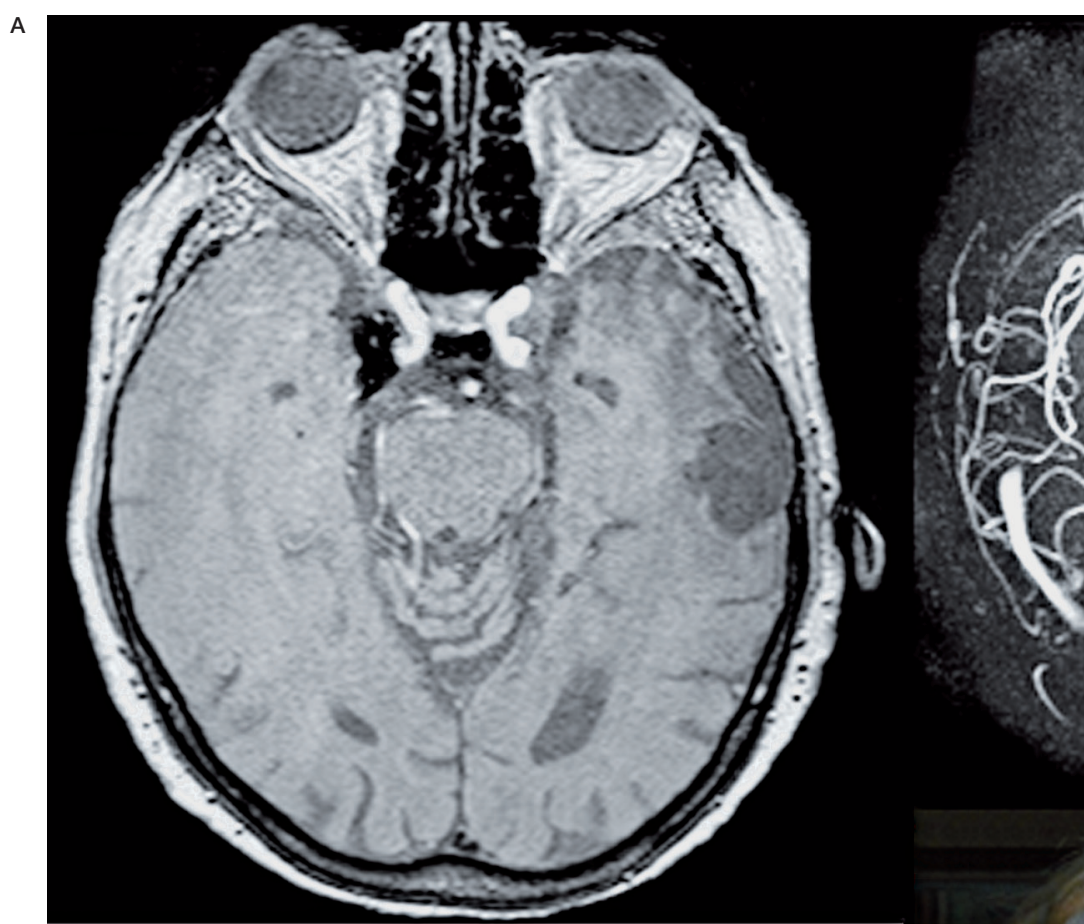

Figure 3 A) Follow-up magnetic resonance angiography: the fistula is still occluded. Outcome of the coiling in the right cavernous sinus and outcome of the head trauma are visible. B) Follow-up magnetic resonance angiography. C) Clinical evaluation: right proptosis, chemosis and ptosis had completely disappeared, whereas bilateral loss of pupillary light reflex and moderate right ophthalmoplegia persisted.

ment (balloon-assisted coiling of the cavernous sinus, access through the ipsilateral IPS) (Figure 2A,B). Seven coils were detached in the cavernous sinus and final angiograms showed complete exclusion of the shunt (Figure 2C). The patient was discharged about one week after treatment. Left proptosis, chemosis and ptosis had regressed; the same symptoms persisted on the right side, even if remarkably reduced. The right ophthalmoplegia was partially cured and bilateral loss of pupillary light reflex persisted (Figure 2D). Radiological and clinical follow-up was performed four years after the procedure; MR and MRA examinations showed persistent

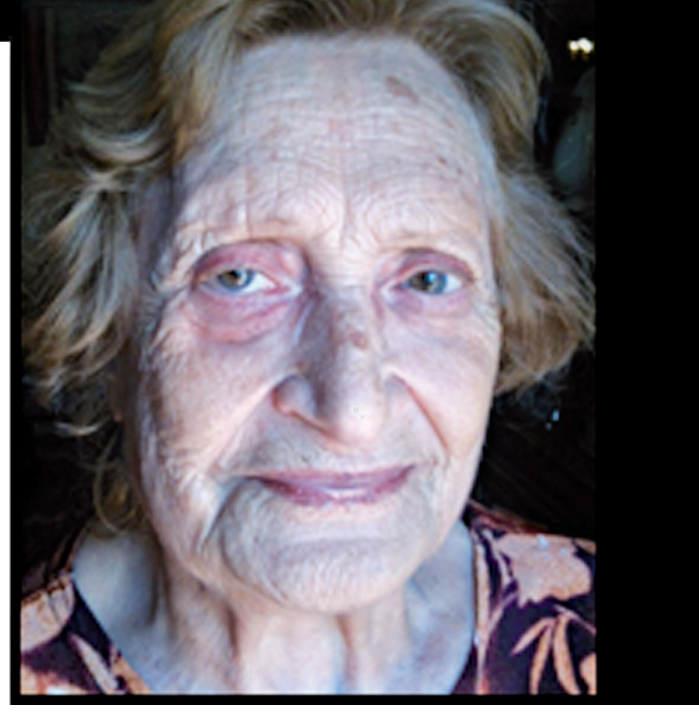

occlusion of the fistula with no visible shunts (Figure 3A,B). Neurological assessment revealed a complete resolution of the right proptosis, chemosis and ptosis, while bilateral loss of pupillary light reflex and moderate right ophthalmoplegia persisted (Figure 3C).

\section{Discussion}

Balloon-assisted coiling of the cavernous sinus for treatment of DCCF was described for the first time by Guglielmi et al. in $1992^{13}$. Subsequently, only a few authors used this tech- 
Table 3 Patients' data and overall results.

\begin{tabular}{|c|c|c|c|c|c|c|c|}
\hline Patient & $\begin{array}{l}\text { Type of } \\
\text { DCCF }\end{array}$ & Technique & Access & CFO D & SR D & $\mathrm{CFO} \mathrm{FU}$ & SR FU \\
\hline 1 & $\mathrm{Thf}$ & BACCS & Ipsilateral ICA & NO & YES & YES & YES \\
\hline 2 & $\mathrm{~T}$ & BACCS & Ipsilateral ICA & NO & YES & YES & YES \\
\hline 3 & $\mathrm{~T}$ & BACCS & Controlateral IPS & NO & YES & YES & YES \\
\hline 4 & S hf & $\operatorname{Tr}$ & Ipsilateral ICA & NO & NO & YES & YES \\
\hline 5 & $\mathrm{~T}$ & BACCS & Ipsilateral ICA & YES & YES & $\mathrm{X}$ & $\mathrm{X}$ \\
\hline 6 & S & BACCS & Ipsilateral IPS & YES & NO & YES & YES \\
\hline $7 *$ & $\mathrm{~T}$ hf & $\begin{array}{l}\text { BACCS/ } \\
\text { BACCS }\end{array}$ & Ipsilateral ICA & NO & YES & $X$ & YES \\
\hline 8 & $\mathrm{~T}$ & BACCS & Ipsilateral IPS & YES & NO & YES & $\mathrm{NO}$ \\
\hline 9 & $\mathrm{~T}$ & BACCS & Ipsilateral ICA & YES & YES & $\mathrm{X}$ & $\mathrm{X}$ \\
\hline 10 & S hf & BACCS & Ipsilateral ICA & YES & YES & YES & YES \\
\hline 11 & $\mathrm{~S}$ & BACCS & Ipsilateral ICA & $\mathrm{NO}$ & YES & $\mathrm{X}$ & $\mathrm{X}$ \\
\hline $12 *$ & $\mathrm{~T}$ hf & $\begin{array}{l}\text { BACCS/ } \\
\text { BACCS }\end{array}$ & Ipsilateral ICA & YES & $\mathrm{X}$ & YES & $\mathrm{X}$ \\
\hline 13 & $S$ & BACCS & Ipsilateral ICA & YES & NO & YES & YES \\
\hline
\end{tabular}

nique 1,10,14,15: in these studies the clinical and radiological results are similar to those observed in our series. On the other hand, the mentioned papers are limited to a small number of patients (two to seven patients). Therefore, to our knowledge, this study comprises the one with the largest number of patients with DCCF treated by balloon-assisted coiling of the cavernous sinus. Semi-compliant balloons were used for three reasons: first, they facilitate the packing of the cavernous sinus. Second, they reduce the risk of coil protrusion into the ICA. Third, the literature does not report a higher risk of ischemic events associated with the use of semi-compliant balloons during coiling procedures ${ }^{16-18}$. In our series, the earliest procedures were performed using the venous approach as first choice whenever the inferior petrous sinus was patent; the arterial approach was considered as second choice in cases of infeasibility of the venous route. Neuroradiological follow-up showed a complete occlusion of the fistula in all patients $(100 \%)$ and no complications occurred. Results obtained with arterial and venous approaches were different, although the number of patients is limited. At discharge the rate of complete occlusion of the fistula was higher in patients treated with a venous approach $(67 \%)$ than in patients treated with arterial approach $(50 \%)$. A possible explanation could be that using the arterial approach coils are positioned and detached closer to the arterial side of the fistula than in the venous approach. Due to the potential risk of migration of the coils into the ICA, the arterial approach would be technically more difficult than the venous one, and in some cases dense packing was not possible. In these cases recovery occurred in second intention, after reconstruction of the ICA wall. This could justify the lower percentages of immediate occlusion of the fistula. With the venous approach coils are located and detached further away from the siphon, and dense packing is more easily achieved. However, follow-up showed a complete occlusion of the fistula in all patients, regardless of the venous or arterial approach. A resolution of symptoms was achieved in higher percentages of patients treated with an arterial rather than venous approach $(78 \%$ and $33 \%$ respectively at discharge, $100 \%$ and $67 \%$ at the end of the follow-up). Persistent symptoms observed during the follow-up were always related to cranial nerve deficits. This could be explained 
by the fact that the arterial approach may avoid the risk of a mass effect in the cavernous sinus that can lead to cranial nerve compression. By contrast, the occlusion of the sinus with more dense packing may lead to complete occlusion of the fistula, also resulting in mass effect and compression on cranial nerves. This could justify the persistent cranial nerve deficit at follow-up in $33 \%$ of patients treated by the venous approach. However, it is not possible to exclude that the deficit was already irreversible at the time of treatment, so that the persistent deficiency would not be related to the technique used. Treatment of direct carotid cavernous fistulas not only aims to alleviate patients' symptoms, but also to prevent SAH, that might occur in untreated or partially treated patients. In view of this, the arterial and venous approaches would seem equivalent, and indeed neuroradiological follow-up showed a complete occlusion of the fistula in all patients, treated with either approach. In one patient $\left(\mathrm{n}^{\circ}\right.$ 7) final angiograms in the first procedure showed complete occlusion of the fistula and a coil tail protrusion into the ICA. The control DSA on the day after treatment after showed rehabilitation of the fistula. A second procedure was hence performed: a self-expandable stent was placed to trap the protruding tail between the vessel wall and the struts of the stent; six more coils were then released in the cavernous sinus. Trapping is a more aggressive technique and, even if no complications occurred in our series, frequent and severe complications associated with ICA sacrifice, such as stroke or blindness, are reported in literature ${ }^{19}$. For this reason trapping should always be considered the last choice, since in our experience the remodeling technique allowed us to preserve the patency of the ICA in 12/13 cases. Sacrifice of the ICA was necessary only in one patient $\left(\mathrm{n}^{\circ}\right.$ 4). In this patient a venous approach was initially attempted, but this failed because of the anatomical variant of both inferior petrosal sinuses (IPSs), which were both plexiform. An arterial approach was then attempted, but placement of the semi-compliant balloon near the ICA laceration proved impossible because of the large diameter of the laceration itself: the microguide repeatedly entered the aneu- rysm sac and it was not possible to gain the exit orifice. After a BOT, occlusion of the ICA was then performed.

Detachable balloons have been used for several years as a first line therapy for the treatment of DCCF; the reported percentages of immediate occlusions ranged between $70 \%$ and $100 \%{ }^{10,20}$. However, three different series of patients, all treated with detachable balloons, showed persistent occlusion of the shunt at the end of the follow-up (range: 2 months- 2 years) in $50 \%, 40 \%$ and $16 \%{ }^{15,20,21}$ of patients. In fact, detachable balloons may have the disadvantage of a possible premature deflation or dislocation; these events could determine a rehabilitation of the fistula and a relapse of symptoms. In addition, detachable balloons can lead to mass effect in the cavernous sinus resulting in permanent or transient cranial nerve palsy. These events are reported up to $20 \%$ of the cases ${ }^{22}$. Endovascular placement of covered stents is being investigated as an alternative to embolization for the treatment of CCFs. Covered stents are deployed within the cavernous ICA, covering the site of the fistula, to exclude the shunt. The reported percentages of immediate exclusion of the fistula are between $62.5 \%$ and $100 \%{ }^{12,23}$. Nevertheless, covered stents are stiff devices that may be navigated with difficulty through tortuous vessels. Therefore, not all patients could be treated with this device. Moreover, delayed thrombosis remains a problem with the use of currently available covered stents in the cerebral circulation ${ }^{12}$ and they can lead to complications such as endoleaks ${ }^{11}$ or the occlusion of arteries originating from the carotid siphon ${ }^{23}$.

\section{Conclusions}

The endovascular treatment of direct carotid cavernous fistulas with balloon-assisted coiling of the cavernous sinus proved effective and safe, both in angiographic and clinical terms, and may provide stable results. Therefore, this may be considered a technical improvement. Follow-up has a fundamental role in monitoring the stability of the treatment and symptom resolution. 


\section{References}

1 van Rooij WJ, Sluzewski M, Beute GN. Ruptured cavernous sinus aneurysms causing carotid cavernous fistula: incidence, clinical presentation, treatment, and outcome. Am J Neuroradiol. 2006; 27: 185-189.

2 Gupta AK, Purkayastha S, Krishnamoorthy T, et al. Endovascular treatment of direct carotid cavernous fistulae: a pictorial review. Neuroradiology. 2006; 48 . 831-839.

3 Huai RC, Yi CL, Ru LB, et al. Traumatic carotid cavernous fistula concomitant with pseudoaneurysm in the sphenoid sinus. Interv Neuroradiol. 2008; 14: 59-68.

4 Halbach VV, Higashida RT, Hieshima GB, et al. Transvenous embolization of direct carotid cavernous fistulas. Am J Neuroradiol. 1988; 9: 741-747.

5 Lewis AI, Tomsick TA, Tew JM Jr. Management of 100 consecutive direct carotid-cavernous fistulas: results of treatment with detachable balloons. Neurosurgery. 1995; 36: 239-245.

6 Kinugasa K, Tokunaga K, Kamata I, et al. Selection and combination of techniques for treating spontaneous carotid-cavernous sinus fistulas. Neurol Med Chir (Tokio). 1994; 34: 597-606.

7 Shownkeen H, Bova D, Origitano TC, et al. Carotidcavernous fistulas: pathogenesis and routes of approach to endovascular treatment. Skull Base. 2001; 11 : 207-218.

8 Bink A, Goller K, Luchtenberg M, et al. Long-term outcome after coil embolization of cavernous sinus arteriovenous fistulas. Am J Neuroradiol. 2010; 31: 1216 1221.

9 Zaidat OO, Lazzaro MA, Niu T, et al. Multimodal endovascular therapy of traumatic and spontaneous carotid cavernous fistula using coils, n-BCA, Onyx and stent graft. J Neurointerv Surg. 2011; 3: 255-262.

10 Tsai YH, Wong HF, Weng HH, et al. Comparison of the risk of oculomotor nerve deficits between detachable balloons and coils in the treatment of direct carotid cavernous fistulas. Am J Neuroradiol. 2010; 31: 11231126.

11 Wang C, Xie X, You C, et al. Placement of covered stents for the treatment of direct carotid cavernous fistulas. Am J Neuroradiol. 2009; 30: 1342-1346.

12 Tiewei Q, Ali A, Shaolei G, et al. Carotid cavernous fistulas treated by endovascular covered stent grafts with follow-up results. Br J Neurosurg. 2010; 24: 435-440.

13 Guglielmi G, Viñuela F, Briganti F, et al. Carotid-cavernous fistula caused by a ruptured intracavernous aneurysm: endovascular treatment by electrothrombosis with detachable coils. Neurosurg. 1992; 31: 591-596.

14 Morris P. Balloon reconstructive technique for the treatment of a carotid cavernous fistula. Am J Neuroradiol. 1999; 20:1107-1109.

15 Yu J, Lei T, Chen J, He Y, et al. Diagnosis and endovascular treatment of spontaneous direct carotid-cavernous fistula. Chin Med J (Engl). 2008; 121: 1558-1562.

16 Spiotta AM, Bhalla T, Hussain MS, et al. An analysis of inflation times during balloon-assisted aneurysm coil embolization and ischemic complications. Stroke. 2011; 42: 1051-1055.

17 Cottier JP, Pasco A, Gallas S, et al. Utility of balloonassisted Guglielmi detachable coiling in the treatment of 49 cerebral aneurysms: a retrospective, multicenter study. Am J Neuroradiol. 2001; 22: 345-351.
18 Layton KF, Cloft HJ, Gray LA, et al. Balloon-assisted coiling of the intracranial aneurysms: evaluation of local thrombus formation and symptomatic thromboembolic complications. Am J Neuroradiol. 2007; 28: 11721175 .

19 Connors JJ, Wojak JC. Interventional neuroradiology: strategies and practical techniques. W.B. Saunders Company, 1999. p. 215-226.

20 Kobayashi N, Miyachi S, Negoro M, et al. Endovascular treatment strategy for direct carotid-cavernous fistulas resulting from rupture of intracavernous carotid aneurysms. Am J Neuroradiol. 2003; 24: 1789-1796.

21 Barry R, Wilkinson M, Ahmed R, et al. Interventional treatment of carotid cavernous fistula. Clin Neurosci. 2011; 18: 1072-1079.

22 Ducruet AF, Albuquerque FC, Crowley RW, et al. The evolution of endovascular treatment of carotid cavernous fistulas: a single-center experience. World Neurosurg. 2013. pii: S1878-8750 (13) 00298-2. doi: 10.1016/j. wneu.2013.02.033. [Epub ahead of print].

23 Gomez F, Escobar W, Gomez AM, et al. Treatment of carotid cavernous fistulas using covered stents: midterm results in seven patients. Am J Neuroradiol. 2007; 28: $1762-1768$.
Arturo Consoli, MD

Interventional Neuroradiology Unit Careggi University Hospital,

Largo Brambilla 3

50134 Firenze, Italy

Tel.: +390557947490

Fax: +39 0557947487

E-mail: onemed21@gmail.com 